\title{
A Climate-Based Model for Predicting Geographic Variation in Swiss Needle Cast Severity in the Oregon Coast Range
}

\author{
Daniel K. Manter, Paul W. Reeser, and Jeffrey K. Stone
}

First author: USDA-Agricultural Research Service, Soil-Plant-Nutrient Research Unit, Fort Collins, CO; and second and third authors: Department of Botany and Plant Pathology, Oregon State University, Corvallis.

Accepted for publication 12 July 2005.

\begin{abstract}
Manter, D. K., Reeser, P. W., and Stone, J. K. 2005. A climate-based model for predicting geographic variation in Swiss needle cast severity in the Oregon Coast Range. Phytopathology 95:1256-1265.

Since the early 1990s, Swiss needle cast disease caused by Phaeocryptopus gaeumannii has been increasing in Douglas-fir plantations in the Oregon Coast Range. Considerable variation in disease severity across the affected area often has been noted. We investigated the influence of site microclimate on fungal colonization as a basis for this variation with a combination of seedling inoculation and field studies. Development of $P$. gaeumannii ascocarps on inoculated seedlings sub-

with temperature. Numbers of ascocarps on foliage, site temperature, and leaf wetness were monitored over 5 years at nine field sites in the Oregon Coast Range. Factors most highly correlated with ascocarp abundance were winter mean daily temperature and spring cumulative leaf wetness. Predictive models for disease severity on the basis of these correlations were tested against disease and climate data measured at field sites during 2003-2004. A temperature-based disease prediction model was developed in combination with geographical information systems (GIS)-linked climate databases to estimate disease levels across a portion of the Oregon Coast Range. This model can be used for hypothesis testing and as a decision support tool for forest managers.
\end{abstract} jected to mist, irrigation, and shading treatments was followed for 10 months. Contrary to expectations, numbers of ascocarps on foliage were negatively correlated with shade and mist and positively correlated
Additional keywords: climate change, Douglas-fir, epidemiology, fungal pathogen, modeling
Following the first reports of Swiss needle cast disease in Europe and the eastern United States, Boyce (1) reported that the causal agent, Phaeocryptopus gaeumannii (Rohde) Petrak, was widespread throughout the Douglas-fir region of western North America but did not cause disease. Boyce noted that although the pathogen was widespread, it was inconspicuous or scarce on native Douglas-fir (Pseudotsuga menziesii (Mirb.) Franco), but produced abundant fruiting bodies on 1- and 2-year-old needles of diseased trees in Europe. Considering the contrasting behavior of $P$. gaeumannii on its host in western North America where its effect was negligible, versus Europe where it was a serious defoliating pathogen, Boyce (1) reasoned that seasonal patterns in local climate might differentially affect fungal growth and development. In particular, Boyce (1) pointed to the warm, humid summers with episodic rain typical of continental Europe as being more conducive to fungal growth, in contrast to the comparatively arid summer climate of the Pacific Northwest. Hood (5) also found evidence of climate effects on the distribution of $P$. gaeumannii in southern British Columbia. Although Hood (5) did not comment on disease severity, he observed a positive correlation between precipitation, particularly spring rainfall, and relative abundance of $P$. gaeumannii.

Since Boyce's (1) first observations, Swiss needle cast disease has become more prevalent in the Pacific Northwest. The disease has been a concern in Christmas tree plantations in the region since the mid 1970s (14), but has been considered of minor importance in forest plantations until recently. Since approximately

Corresponding author: D. K. Manter; E-mail address: daniel.manter@ars.usda.gov

DOI: $10.1094 /$ PHYTO-95-1256

This article is in the public domain and not copyrightable. It may be freely reprinted with customary crediting of the source. The American Phytopathological Society, 2005
1990, severe chlorosis, defoliation, and growth reduction because of Swiss needle cast have been increasing in forest plantations of western Oregon (4), and currently the disease affects approximately 120,000 ha of Douglas-fir plantations in the Coast Range (7).

Several aspects of the current Swiss needle cast epidemic in western Oregon also suggest that differences in local climate may be important determinants of disease severity. Accumulating evidence supports Boyce's (1) suggestion that environmental factors that favor growth of the fungus may allow disease to reach epidemic levels, even in the area where it is native. The pathogen is widely distributed and abundant throughout Douglas-fir stands in western Oregon, so it may be assumed that restrictions to dissemination of ascospores in Coast Range forests are at most very slight. Yet severity of disease ranges from negligible in some stands to severe in others (4).

The spatial distribution of Swiss needle cast in coastal Oregon observed over the past several years suggests a relationship between disease severity and local climate. Observations obtained from the Oregon Department of Forestry aerial survey, conducted annually since 1996, consistently found more severe disease symptoms in stands nearest the coast, gradually lessening inland (7). More severe symptoms (chlorosis and defoliation) on south aspect slopes also have been reported by various observers $(12,18)$. We have monitored defoliation due to disease together with the abundance of fruiting bodies (pseudothecia) on 1- and 2-year-old foliage at nine sites in the Oregon Coast Range since 1996. While both measures of disease severity at these sites have fluctuated somewhat from year to year, the relative ranking of the sites with respect to disease severity has remained fairly constant $(4,23)$, suggesting that site-related factors may be important determinants of disease severity.

Rosso and Hansen (18) reported correlations between Swiss needle cast symptom severity in Coast Range plantations and 
several climate and topographic variables. The strongest predictor $\left(R^{2}=0.57\right)$ of stand disease rating (an index based on several visual disease symptoms) was a regression model that included mean maximum July temperature, mean July precipitation, July fog occurrence, and aspect. Although this model explained approximately $60 \%$ of the observed variation in stand disease rating, it was not useful for predicting defoliation $\left(R^{2}=0.29\right)$.

Because the most severe disease has been observed in sites within the low elevation coastal fog zone (so called because of the frequency of summer maritime fog), the amount of free water on foliage in the summer has been considered a possible factor affecting disease severity $(4,18)$. Other investigators have noted an apparent relationship between geographic precipitation patterns and abundance of the pathogen in the Pacific Northwest $(5,13)$. However, several other environmental variables also co-vary with these spatial effects (temperature, light, leaf wetness, and plant water content). We therefore, implemented a study to investigate the relative importance of individual climate factors by season to better understand their influence on different phases of the infection cycle and rate of colonization of foliage by P. gaeumannii. We then used this information in combination with field measurements to develop and test predictive models for distribution and severity of Swiss needle cast disease in western Oregon. Whereas Rosso and Hansen (18) investigated the correlations between climate factors and disease symptoms in forest stands, the goal of this study was to develop a disease prediction model based on climatic factors that directly influence the growth rate and abundance of $P$. gaeumannii.

\section{MATERIALS AND METHODS}

Seedling inoculation. One-year-old Douglas-fir seedlings (Burnt Woods open-pollinated seed source, Starker Forests, Inc., Corvallis, OR) were produced in an enclosed container nursery, transplanted into 7.6-liter (2-gallon) plastic pots with potting media and exposed to natural inoculum at a moderately diseased coastal Oregon plantation (Salal plantation; Table 1) for 4 weeks in June 2000. After inoculation, seedlings were relocated to Corvallis, OR and incubated under different levels of shade, irrigation, and mist treatments for 10 months (July-April) at ambient temperature. Postinoculation environment treatments were applied in a randomized, complete, split-plot design with a factorial arrangement of overhead mist and shade treatments applied to whole plots and irrigation treatments applied to subplots (i.e., seedlings). Mist treatments consisted of either no mist or mist applied for 2-h periods three times daily. Shade treatments were either 100 or $50 \%$ of ambient light provided by a shade cloth suspended above the seedlings. Irrigation treatments were 1.9 or 0.5 liter of water per day, applied by drip emitters. The 12 incubation chambers were $0.9 \times 1.8 \times 1.2 \mathrm{~m}$ frames constructed from 2.54-cm (1-in.) diameter polyvinylchloride pipe to support shade cloth and mist tubing. Each chamber held six trees, and the two irrigation treatments were applied to three trees in each of the 12 chambers. Chambers were grouped in three replicate blocks.

Each chamber was equipped with two leaf wetness/temperature dataloggers (Spectrum Technologies, Plainfield, IL) and observations were recorded hourly. To verify that the different levels of irrigation affected soil water availability, assessments of plantwater stress were determined by measuring predawn (0400 to $0600 \mathrm{~h}$ ) xylem pressure potentials ( $\left.\Psi_{\text {leaf }}\right)$ with a pressure chamber (PMS Instruments, Corvallis, OR) in August 2000. For each incubation chamber, one seedling from each irrigation treatment was randomly selected for $\Psi_{\text {leaf }}$ measurement $(n=12)$.

The amount of fungal colonization was estimated at monthly intervals by visual assessments of numbers of $P$. gaeumannii ascocarps (pseudothecia) on needles. At each sampling date, 50 needles for each seedling were arbitrarily selected and removed from three branchlets for each seedling. The needles were affixed to index cards with double-sided adhesive tape, and examined with a binocular dissecting microscope at $\times 40$ to determine the proportion of needles bearing pseudothecia (incidence of infection). The first 10 needles on each card with pseudothecia present were then used to determine the proportion of stomata occluded by pseudothecia (pseudothecia density). The needles were examined with a dissecting microscope fitted with a counting grid and the proportion of stomata occluded by pseudothecia in three, 2.6- $\times 0.26-\mathrm{mm}$ segments (base, middle, tip) of each of the 10 needles was determined and averaged. An infection index $(I)$, the product of the percent of needles with visible pseudothecia (incidence, $n=50$ ) and the average proportion of stomata occluded (pseudothecia density, $n=10$ ), was used as a response variable for comparisons of treatments. Statistical analyses of differences in $I$ between treatments in the postinoculation seedling study were carried out by PROC Mixed with Fisher's LSD multiple comparison procedure (SAS version 8; SAS Institute, Cary, NC).

Field observations. Measurements of $P$. gaeumannii pseudothecial abundance, temperature, and leaf wetness were made over a 5-year period from 2000 to 2004 in nine Douglas-fir plantations. The nine sites were grouped in three clusters of three sites (north, central, and south) near Tillamook, OR (Table 1). The sites in each group were located in Douglas-fir plantations of a similar age, ca. 12 to 15 years, and where possible, the same seed source. Study sites were selected to represent a range of elevations, distances from maritime influences, and disease severity. One site in each cluster had moderate to heavy symptoms of Swiss needle cast and one site was classified as having mild disease, although $P$. gaeumannii was present at all sites.

The southern sites comprised three USDA Forest Service progeny test plantations. Ten trees from each of two families were

TABLE 1. Characteristics of field sites used for observations on the relationship between Phaeocryptopus gaeumannii abundance and environmental factors

\begin{tabular}{|c|c|c|c|c|c|c|c|}
\hline Site & Group & Disease severity & Elevation (m) & Distance inland $\mathrm{d}^{\mathrm{a}}$ & Age (2001) & Seed source & Aspect \\
\hline Acey Creek ${ }^{b}$ & North & Healthy & 205 & 13 & 15 & USFS progeny test & $\mathrm{E}$ \\
\hline Coal Creek ${ }^{\mathrm{b}}$ & North & Moderate & 70 & 8 & 15 & USFS progeny test & SE \\
\hline North Fork ${ }^{\mathrm{b}}$ & North & Severe & 50 & 8 & 15 & Boundary & SW \\
\hline Lower Stone $^{\mathrm{b}}$ & Central & Mild & 130 & 24 & 19 & Boundary & SW \\
\hline Juno Hill, & Central & Severe & 115 & 3 & 19 & Boundary & $\mathrm{NE}$ \\
\hline Limestone $^{\mathrm{b}, \mathrm{c}}$ & South & Healthy & 270 & 20 & 14 & USFS progeny test & $\mathrm{N}$ \\
\hline Cedar North ${ }^{\mathrm{b}, \mathrm{c}}$ & South & Mild & 460 & 12 & 14 & USFS progeny test & NW \\
\hline MacDonald $^{\mathrm{c}}$ & East & Healthy & 245 & 75 & 15 & unknown & $\mathrm{N}$ \\
\hline Roth $^{\mathrm{c}}$ & East & Healthy & 185 & 37 & 12 & unknown & SW \\
\hline
\end{tabular}

${ }^{a}$ Kilometers inland from the ocean or bay.

${ }^{\mathrm{b}}$ Sites used for model development 2000-2002.

c Sites used for model testing 2003-2004. 
arbitrarily selected for measurements in each plantation. Sites in the central area all had been planted with seedlings from the same bulk seed lot, from the "Boundary" seed collection area of the Coast Range, at approximately 600-m elevation. Ten trees in each plantation were arbitrarily selected for measurements. The northern sites included one site also planted with the Boundary seed source (North Fork) and two Oregon Department of Forestry progeny test plantations. Ten trees from each of two families (different from the southern sites) were selected for measurements in each of the latter plantations and 10 randomly selected trees were measured at North Fork. Three additional study sites, Dolph, MacDonald forest, and Roth forest (Table 1), were established in 2002 and sampled in 2003 and 2004 as part of the model testing data set.

Each study site was equipped with two leaf wetness/temperature dataloggers (Spectrum Technologies) and observations were
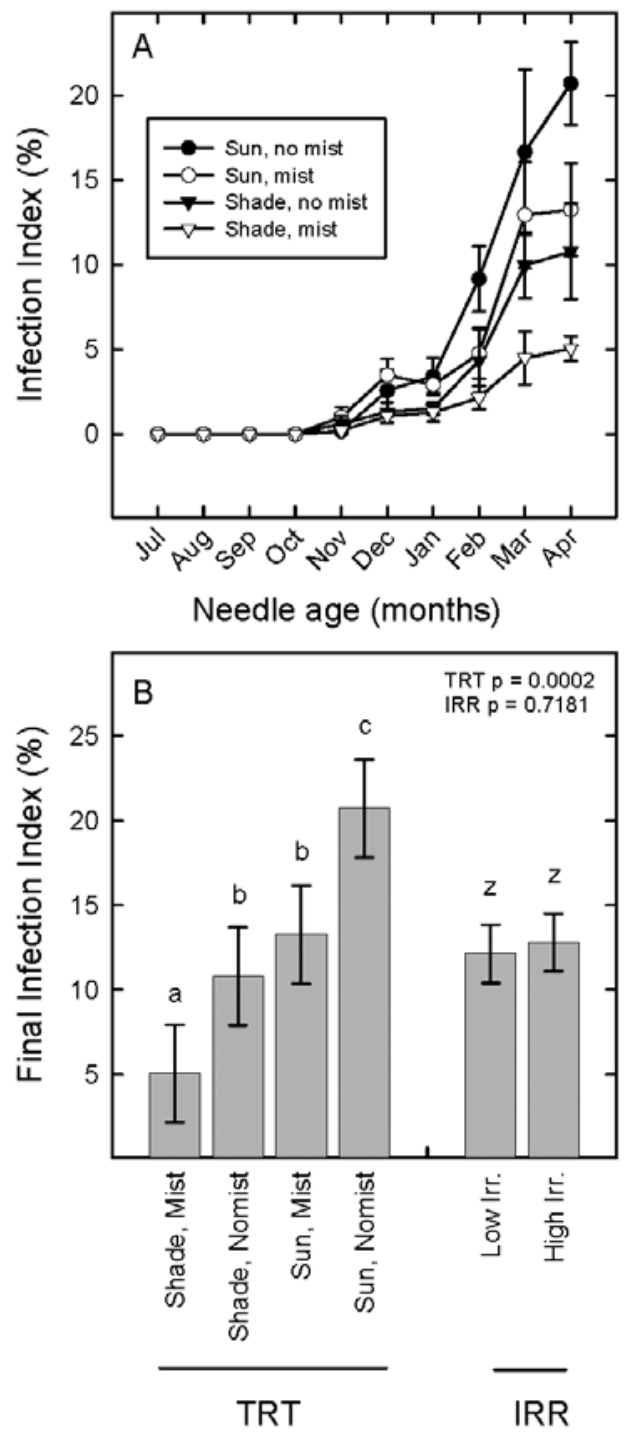

Fig. 1. Effect of postinoculation incubation conditions on development and abundance of Phaeocryptopus gaeumannii pseudothecia. A, Monthly development of pseudothecia in four shade/mist combinations. $\triangle=$ shade, mist; $\boldsymbol{\nabla}=$ shade, no mist; $O=$ sun, mist; and $\bullet=$ sun, no mist. B, Final infection index values at 10 months following inoculation for seedlings exposed to shade, mist, and irrigation treatments $(P$ (shade $/$ mist $)=0.0002$, $P($ Irr $)=0.7181)$. Sun $=100 \%$ ambient, shade $=50 \%$ ambient, mist $=$ three $2-\mathrm{hr}$ overhead mist treatments per day, no mist $=0$ overhead mist treatments per day ( ambient humidity), low irr. $=0.5 \mathrm{~L} \mathrm{day}^{-1}$ drip irrigation, and high irr. $=$ $1.9 \mathrm{~L} \mathrm{day}^{-1}$ drip irrigation. Bars are the arithmetic means and individual standard errors. Treatment effects were analyzed using a split-randomized complete block design and bars with different letters are significant at $P<0.05$. recorded hourly. Foliage collections for disease assessments were made annually in late April from all selected trees at each site. Two lateral branches were collected from the midcrown (fifth whorl below the terminal shoot) for each tree sampled per site. Four to six 1- and 2-year-old internodes were clipped from the branches, placed in labeled bags, and returned to the lab. Needles were then stripped off and pooled by age class. A sample of 50 needles for each age class per tree was randomly drawn and affixed to index cards and incidence, pseudothecia density, and $I$ were determined as described above.

Model derivation and testing. Site-specific climate factors (cumulative leaf wetness hours $[L W]$ and average daily temperature $[T]$ ) were separated into three seasonal periods and subjected to stepwise regression (Statgraphics; Manugistics Inc., Rockville, MD) against infection indices for 1- and 2-year-old needles to identify the best climate-only model for $I$ prediction. The three seasonal periods were selected to represent major phases of the infection cycle (2): spring (May-July), corresponding to the period when spore deposition and initial infection occur; summer (August-October), corresponding to the period of needle colonization by internal hyphal growth; and winter (December-February), corresponding to the period when proliferation of pseudothecia occurs. Correlations between infection indices and seasonally grouped climate data were performed using the contemporaneous annual climate measurements for each needle age class measured (e.g., I for the 1-year-old needle cohort sampled in April 2001 was correlated with corresponding May 2000-April 2001 climate data).

Because of the perennial foliage of Douglas-fir, the amount of $P$. gaeumannii in current-year foliage may be affected by the amount of infection in foliage produced and infected in preceding years. Therefore, two additional disease-related variables were included in the model equations. For predicting $I$ in foliage at 12 months following emergence (1-year-old needles), $I$ of the previous-year needle cohort measured in the current year (i.e., 2-yearold needles) was included as a term in the equation (e.g., I measured in April 2000 for the 1998 needle cohort was used for predicting $I$ for the1999 needle cohort in 2000). This term, $I_{\mathrm{y}-2}$, was assumed to be a predictor of inoculum exposure of newly emerged, previously uninfected needles. For predicting infection levels in foliage at 24 months following emergence (2-year-old needles), $I$ for the same needle cohort measured the previous spring was included as a term in the equation (e.g., for predicting $I$ for the 1998 needle cohort in 2000, I for the same needle cohort measured in April 1999 was used). This term, $I_{\mathrm{y}-1}$, was assumed to be a predictor of initial colonization levels in needles at the beginning of the needles' second year. These two variables, $I_{\mathrm{y}-2}$ and $I_{\mathrm{y}-1}$, were included in a combined climate-disease model that was used to iteratively determine equilibrium $I$ levels for 1- and 2-year old foliage at selected fixed values of $T$. This model also was used to retrospectively simulate annual fluctuations in $I$ for 1980-2002 on the basis of historical mean daily winter temperature data from Tillamook, OR (Tillamook Weather Station 1W, 35894, NOAA, National Weather Service). Iterations were carried out by means of linked spreadsheet cells (Microsoft Excel).

Climate-only and climate-disease models were derived from measurements of $I$ for 1 - and 2-year-old needles at the nine field sites in 2000-2002. The predictive capability of the selected models was evaluated by comparisons with 2003-2004 measurements of infection index from four of the original nine sites, plus three sites not used previously (Table 1).

Climate database and disease prediction map. The DAYMET database was used to construct a Swiss needle cast disease prediction map on the basis of mean daily winter temperature for a portion of western Oregon. The DAYMET climate model (Numerical Terradynamic Simulation Group, University of Montana, Missoula; http://www.daymet.org) uses a weighting algorithm and digital elevation model to generate daily surfaces of 
temperature, precipitation, humidity, and solar radiation by interpolation from observations from ground-based meteorological stations (NOAA, National Weather Service). The DAYMET climate model is a continuous surface of temperature, precipitation, humidity, and radiation for the conterminous United States at 1-km resolution based on 18-year (1980-1997) daily averages.

\section{RESULTS}

Seedling inoculation. The postinoculation incubation conditions differentially affected the rates of foliage colonization by $P$. gaeumannii. At 10 months following inoculation, the amount of $P$. gaeumannii colonization, as measured by $I$, was significantly less for the shade with mist treatment than it was for the full sun, no mist treatment. $I$ values for all treatments ranged from 5.1 to 20.7 (Fig. 1A). Despite a significant effect on plant-water stress (i.e., predawn $\Psi_{\text {leaf }}$ of $-0.4 \pm 0.1$ and $-1.8 \pm 0.2 \mathrm{MPa}$ for the highand low-irrigation treatments in August 2000, respectively), irrigation did not have a significant effect on numbers of pseudothecia (Fig. 1B).

Colonization by $P$. gaeumannii followed an exponential growth curve for all treatments, with the greatest increases occurring during the winter months of January and February (Fig. 1A). Differences in $I$ between treatments were first detectable in NovemberDecember and continued to diverge during the subsequent winter and spring months. After 10 months, $I$ was greatest in the no shade, no mist treatment, smallest in the shade with mist treatment, and intermediate in the other two treatments (Fig. 1B). A regression of final $I$ against average daily winter temperature for the four treatments (December-February) revealed a linear relationship between treatment mean temperature and the final $I\left(R^{2}=\right.$ 0.925).

Field observations. Values for P. gaeumannii I determined annually during 2000-2004 at the nine coastal Douglas-fir plantations are shown in Table 2. Amounts of $P$. gaeumannii within sites fluctuated somewhat during the 5 years of observation (e.g., 14.0 to 24.7 and 0.6 to 2.3 for the sites with the highest and lowest infection levels in 1-year-old needles). No consistent changes (increase or decrease) in $I$ were observed for site groups, although $I$ declined between 2000-2004 at Juno Hill, the site consistently having the greatest $I$ and most severe disease. With respect to $I$, the relative ranking of sites remained generally consistent from year to year (Table 2). The relative rankings of sites with respect to $L W$ and $T$ grouped by season also were relatively consistent from year to year, although with considerable annual variation in absolute values, and tended to parallel the rankings by $I$ (Table 2).
Correlations between seasonal climate variables and P. gaeumannii I for the nine coastal sites are shown in Table 3. Average winter daily temperature $\left(T_{\text {winter }}\right)$ was the only climate variable with $R$ values above $0.85, L W$ and $T$ for the other seasonal periods had correlation coefficients of 0.5 or less. Consistently high correlations $(R=0.85$ to 0.96$)$ also were found between $I$ for 1 - and 2 -year-old needles and the corresponding prior year infection indices, $I_{\mathrm{y}-2}$ and $I_{\mathrm{y}-1}$ (Table 3 ).

Model derivation and testing. Three models, each comprising a pair of equations for the prediction of $I$ in 1- and 2-year-old needles, were generated by stepwise regression on the results from field studies. The first model, hereafter called the climateonly model, included the $L W_{\text {spring }}$ and $T_{\text {winter }}$ variables and was the best-fit model for predicting infection in both needle age classes, with $R^{2}$ values of 0.781 and 0.772 for 1 - and 2-year-old needles, respectively (Table 4 and Fig. 2). This climate-only model was

TABLE 3. Pearson correlation coefficients $(r)$ for relationships between infection indices $(I)$ for Swiss needle cast of Douglas-fir and weather variables measured at nine sites in the Oregon Coast Range

\begin{tabular}{|c|c|c|c|c|}
\hline Variable $1^{\mathrm{a}}$ & Variable 2 & $2000^{\mathrm{b}}$ & 2001 & 2002 \\
\hline$I$ (1-year-old) & $\begin{array}{l}I_{\mathrm{y}-2}{ }^{\mathrm{c}} \\
T_{\text {winter }}^{\mathrm{d}} \\
T_{\text {summer }} \\
T_{\text {spring }} \\
L W_{\text {winter }}^{\mathrm{e}} \\
L W_{\text {summer }} \\
L W_{\text {spring }}\end{array}$ & $\begin{array}{c}0.952 \\
\ldots \\
0.295 \\
0.719 \\
\ldots \\
0.361 \\
-0.138\end{array}$ & $\begin{array}{r}0.906 \\
0.959 \\
0.418 \\
0.286 \\
-0.461 \\
0.274 \\
0.402\end{array}$ & $\begin{array}{r}0.941 \\
0.933 \\
0.521 \\
0.378 \\
-0.464 \\
0.289 \\
0.116\end{array}$ \\
\hline$I$ (2-year-old) & $\begin{array}{l}I_{\mathrm{y}-1} \mathrm{f} \\
T_{\text {winter }} \\
T_{\text {summer }} \\
T_{\text {spring }} \\
L W_{\text {winter }} \\
L W_{\text {summer }} \\
L W_{\text {spring }} \\
\end{array}$ & $\begin{array}{c}0.956 \\
\ldots \\
0.083 \\
0.683 \\
\ldots \\
0.537 \\
-0.041 \\
\end{array}$ & $\begin{array}{l}0.919 \\
0.873 \\
0.418 \\
0.298 \\
0.107 \\
0.498 \\
0.564 \\
\end{array}$ & $\begin{array}{l}0.849 \\
0.888 \\
0.460 \\
0.361 \\
0.361 \\
0.542 \\
0.389 \\
\end{array}$ \\
\hline
\end{tabular}

${ }^{a}$ Infection index $(I)$ is the product of incidence of infection $(n=50)$ and pseudothecia density $(n=10)$.

b Needles were sampled in late April of the year denoted, e.g., in 2000, the 1999 and 1998 needle age classes are the 1- and 2-year-old needles, respectively.

${ }^{c} I_{\mathrm{y}-2}$ is the infection index of the 2-year-old needle cohort sampled in the current year.

${ }^{\mathrm{d}} T$ is mean daily temperature. Winter is December, January, and February; spring is May, June, and July; and summer is August, September, and October.

${ }^{\text {e }} L W$ is cumulative leaf wetness hours.

${ }^{\mathrm{f}} I_{\mathrm{y}-1}$ is the infection index of the 2-year-old needle cohort at the beginning of the second growing season (i.e., at 12 months after emergence).

TABLE 2. Five-year summary of the percentage of stomata occluded by Phaeocryptopus gaeumannii pseudothecia (infection index [I $]^{\text {a) }}$ in 1 - and 2-year-old needles for nine coastal study sites used for model development and seven sites used for model testing

\begin{tabular}{|c|c|c|c|c|c|c|c|c|c|c|}
\hline \multirow[b]{2}{*}{ Site } & \multicolumn{5}{|c|}{ One-year-old needles } & \multicolumn{5}{|c|}{ Two-year-old needles } \\
\hline & $2000^{\mathrm{b}}$ & 2001 & 2002 & 2003 & 2004 & 2000 & 2001 & 2002 & 2003 & 2004 \\
\hline Acey Creek ${ }^{\mathrm{c}}$ & 7.4 & 2.8 & 1.6 & $\ldots$ & $\ldots$ & 19.6 & 16.5 & 15.4 & $\ldots$ & $\ldots$ \\
\hline Coal Creek ${ }^{\mathrm{c}}$ & 9.7 & 6.3 & 2.4 & $\ldots$ & $\ldots$ & 25.2 & 22.7 & 15.7 & $\ldots$ & $\ldots$ \\
\hline North Fork ${ }^{\mathrm{c}}$ & 16.8 & 7.0 & 9.8 & $\ldots$ & $\ldots$ & 48.6 & 38.9 & 35.7 & $\ldots$ & $\ldots$ \\
\hline Upper Stone $^{\mathrm{c}}$ & 3.0 & 2.2 & $\ldots$ & $\ldots$ & $\ldots$ & 20.9 & 14.9 & $\ldots$ & $\ldots$ & $\ldots$ \\
\hline Lower Stone ${ }^{c}$ & 9.5 & 1.5 & $\ldots$ & $\ldots$ & $\ldots$ & 28.3 & 19.6 & $\ldots$ & $\ldots$ & $\ldots$ \\
\hline Juno Hille,d & 24.7 & 16.6 & 16.3 & 22.8 & 14.0 & 52.5 & 47.0 & 39.3 & 35.0 & 27.2 \\
\hline Limestone $^{\mathrm{c}, \mathrm{d}}$ & 4.3 & 1.0 & 2.0 & 4.6 & 0.3 & 16.7 & 19.2 & 13.3 & 18.0 & 12.5 \\
\hline Cedar North ${ }^{\mathrm{c}, \mathrm{d}}$ & 2.3 & 1.0 & 0.7 & 2.3 & 0.6 & 17.8 & 20.3 & 12.5 & 17.6 & 14.4 \\
\hline Salal ${ }^{\mathrm{c}, \mathrm{d}}$ & 4.9 & 4.2 & 2.5 & 7.4 & 1.5 & 23.0 & 24.4 & 23.2 & 19.8 & 21.5 \\
\hline Dolph $^{\mathrm{d}}$ & $\ldots$ & $\ldots$ & $\ldots$ & 8.4 & 0.8 & $\ldots$ & $\ldots$ & $\ldots$ & 29.9 & 23.2 \\
\hline MacDonald $^{\mathrm{d}}$ & $\ldots$ & $\ldots$ & $\ldots$ & 0 & 0 & $\ldots$ & $\ldots$ & $\ldots$ & 0.3 & 0.6 \\
\hline Roth $^{\mathrm{d}}$ & $\ldots$ & $\ldots$ & $\ldots$ & 1.4 & 0.4 & $\ldots$ & $\ldots$ & $\ldots$ & 11.7 & 15.3 \\
\hline
\end{tabular}

${ }^{a}$ Infection index $(I)$ is the product of incidence of infection $(n=50)$ and pseudothecia density $(n=10)$.

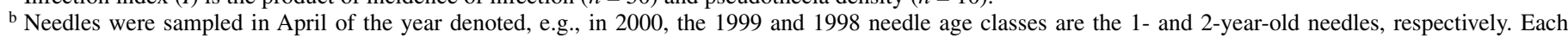
value is the individual site mean $(n=20)$.

c Sites used for model development 2000-2002.

d Sites used for model testing 2003-2004. 
tested against $I, T_{\text {winter}}$, and $L W_{\text {spring }}$ measurements made during 2003-2004 from seven field sites. Predictions generated with the climate-only model showed a highly significant 1:1 relationship with observed values of infection indices $\left(y=2.55+0.986 x, R^{2}=\right.$ 0.802, Fig. 3A).

Because leaf wetness data are not readily available from public meteorological databases, a second model was sought which could be used for $I$ predictions and historical simulations over a regional scale without requiring leaf wetness data. $T_{\text {winter }}$ was the best single-factor predictor of $I$ (Table 3), however, its relationship with $I$ varied by year (Fig. 4), suggesting that additional factors were influencing infection. Therefore, the two disease component variables $\left(I_{\mathrm{y}-2}\right.$ and $\left.I_{\mathrm{y}-1}\right)$ were included in a second pair of equations with $T_{\text {winter }}$. Values of $I$ obtained with this model, hereafter called the climate-disease model, were highly correlated with observed values for 1-year-old $\left(R^{2}=0.906\right)$ and 2-year-old needles $\left(R^{2}=0.803\right)$ used for model derivation, independent of year (Fig. 5). Predictions of $I$ generated by the climate-disease model showed a highly significant 1:1 relationship with observed values of infection indices for the model validation data $(y=$ $0.356+1.072 x, R^{2}=0.812$, Fig. 3B).

The climate-disease model was then used to iteratively predict infection levels with winter temperature held constant over a range of temperature values $\left(2\right.$ to $\left.10^{\circ} \mathrm{C}\right)$. For example, given any initial $I$ for 2-year-old needles $\left(I_{\mathrm{y}-2}\right)$, the infection index for 1 -year-old needles the following year can be predicted for any value of $T_{\text {winter }}$. From this result (which becomes $I_{\mathrm{y}-1}$ ), the $I$ for 2-year-old needles can be predicted given any value of $T_{\text {winter }}$. This series of calculations was repeated to simulate $P$. gaeumannii infection levels over a period of several years at a constant $T_{\text {winter }}$ $\left(5.13^{\circ} \mathrm{C}\right.$, the average value from the nine study sites) and a very low initial $I$ of $1.0 \%$ (Fig. 6A). In this scenario, $I$ for 1 - and 2 -year-old needles increased quickly and after five iterations reached a constant, temperature-dependent value. When this same exercise was conducted over a range of $T_{\text {winter }}$ values, the final maximum value of $I$ was linearly related to $T_{\text {winter }}$ (1-year-old needles: $I=-13.7+3.36\left(T_{\text {winter }}\right), R^{2}=0.999 ; 2$-year-old needles: $I=$ $\left.-10.8+5.85\left(T_{\text {winter }}\right), R^{2}=0.999\right)$.

A similar series of iterations was carried out to simulate historical annual variations in P. gaeumannii abundance for 1980-2002 based on weather data from Tillamook, OR (Tillamook Weather Station 1W, 358494, National Weather Service). In this simulation, the 1980 initial $I$ was arbitrarily set at $1.0 \%$ and the actual average mean daily temperature recorded for each year was used for $T_{\text {winter }}$. As was observed for the fixed temperature simulations, $P$. gaeumannii levels initially increased rapidly to the temperature-limited value and then fluctuated with annual variations in winter temperature (Fig. 6B).

Disease prediction map. Because the predicted maximum value of $I$ in the climate-disease model is a function of $T_{\text {winter }}$, regardless of the initial infection level, this model, i.e., the maxi- mum value of $I$ for a fixed value of $T_{\text {winter }}$ generated by the climate-disease model, hereafter referred to as the equilibrium model, may be suitable for simulations of geographic variation in Swiss needle cast severity based solely on temperature records from weather data archives. Predictions generated using the equilibrium model showed a highly significant $1: 1$ relationship with observed values of infection indices $\left(y=3.635+0.766 x, R^{2}=\right.$ 0.701 , Fig. $3 C$ ). The ability to estimate equilibrium $P$. gaeumannii

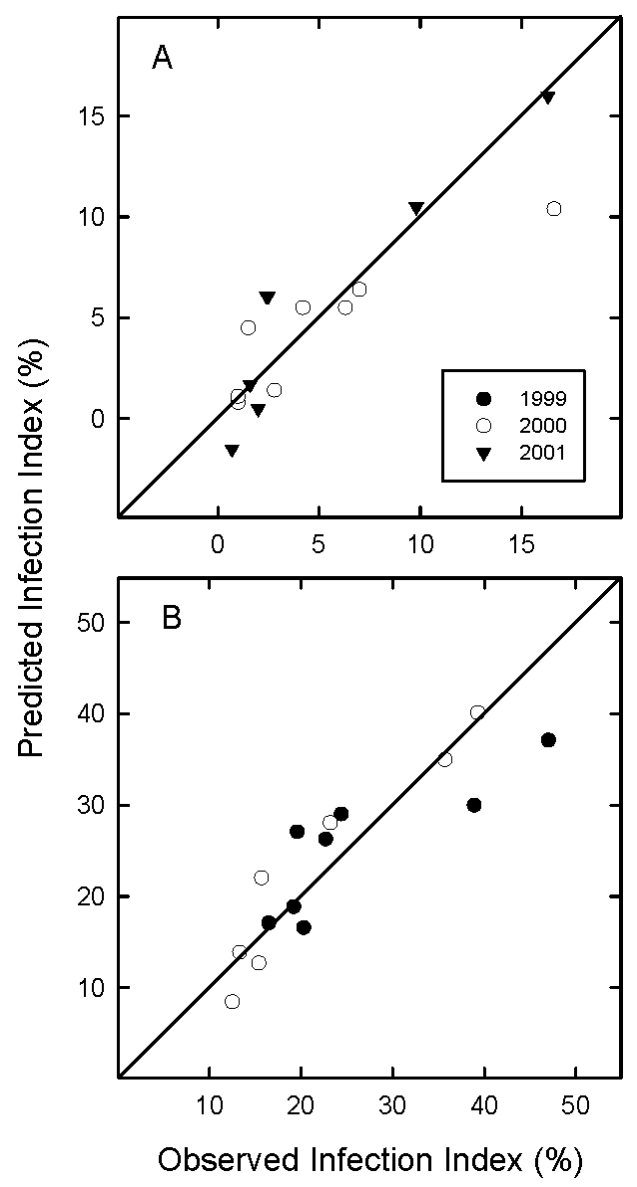

Fig. 2. Best-fit climate-only models for data from nine coastal field sites from 2000-2002. Comparison between observed versus predicted Phaeocryptopus gaeumannii infection index $(I)$ for the selected models. A, One-year-old needles $\left(I=-18.1+5.86 \times 10^{-3}\left(L W_{\text {spring }}\right)+3.38\left(T_{\text {winter }}\right), R^{2}=0.781\right)$. B, Twoyear-old needles $\left(I=-30.0+2.35 \times 10^{-2}\left(L W_{\text {spring }}\right)+6.05\left(T_{\text {winter }}\right), R^{2}=0.772\right)$. $L W_{\text {spring }}$ is the total leaf wetness hours for the months of May and June, and $T_{\text {winter }}$ is average mean daily winter temperature for the months of December and Febraury. $\boldsymbol{\nabla}=2001$ needle cohort, $\mathrm{O}=2000$ needle cohort, and $\bullet=$ 1999 needle cohort.

TABLE 4. Five best-fit regression model selections for predicting Phaeocryptopus gaeumannii infection index (I) in 1- and 2-year-old needles based on seasonally grouped weather variables

\begin{tabular}{|c|c|c|c|c|c|}
\hline & Mean square error & $R^{2}$ & Adj. $R^{2}$ & Mallow's Cp & Variables $^{\mathrm{a}}$ \\
\hline$I$ (1-year-old needles) & $\begin{array}{l}7.03 \\
\mathbf{7 . 1 7 ^ { \mathrm { b } }} \\
6.54 \\
6.65 \\
7.39\end{array}$ & $\begin{array}{l}0.785 \\
\mathbf{0 . 7 8 1} \\
0.817 \\
0.814 \\
0.774\end{array}$ & $\begin{array}{l}0.749 \\
\mathbf{0 . 7 4 5} \\
0.767 \\
0.763 \\
0.736\end{array}$ & $\begin{array}{l}2.935 \\
\mathbf{3 . 1 6 3} \\
3.181 \\
3.339 \\
3.548\end{array}$ & $\begin{array}{l}L W_{\text {winter }}, T_{\text {winter }} \\
\boldsymbol{L} \boldsymbol{W}_{\text {spring }}, \boldsymbol{T}_{\text {winter }} \\
L W_{\text {summer }}, L W_{\text {winter }}, T_{\text {winter }} \\
L W_{\text {spring, }}, L W_{\text {winter }}, T_{\text {winter }} \\
L W_{\text {summer }}, T_{\text {winter }}\end{array}$ \\
\hline$I$ (2-year-old needles) & $\begin{array}{l}\mathbf{3 0 . 9}^{\mathrm{b}} \\
31.9 \\
30.1 \\
31.9 \\
29.2\end{array}$ & $\begin{array}{l}\mathbf{0 . 7 7 2} \\
0.765 \\
0.797 \\
0.784 \\
0.820\end{array}$ & $\begin{array}{l}\mathbf{0 . 7 3 4} \\
0.725 \\
0.741 \\
0.725 \\
0.749\end{array}$ & $\begin{array}{l}\mathbf{2 . 7 5 6} \\
3.139 \\
3.490 \\
4.132 \\
4.263\end{array}$ & $\begin{array}{l}\boldsymbol{L} \boldsymbol{W}_{\text {spring }}, \boldsymbol{T}_{\text {winter }} \\
L W_{\text {summer }}, T_{\text {winter }} \\
L W_{\text {spring }}, L W_{\text {summer }}, T_{\text {winter }} \\
L W_{\text {summer }}, T_{\text {summer }}, T_{\text {winter }} \\
L W_{\text {summer }}, T_{\text {spring }}, T_{\text {summer }}, T_{\text {winter }}\end{array}$ \\
\hline
\end{tabular}

${ }^{a} T$ is mean daily temperature. $L W$ is cumulative leaf wetness hours. Winter is December, January, and February; spring is May, June, and July; and summer is August, September, and October.

${ }^{\mathrm{b}}$ Chosen models in bold face type: $I(1$-year-old $)=-18.1+5.86 \times 10^{-3}\left(L W_{\text {spring }}\right)+3.38\left(T_{\text {winter }}\right) ; I(2$-year-old $)=-30.0+2.35 \times 10^{-2}\left(L W_{\text {spring }}\right)+6.05\left(T_{\text {winter }}\right)$. 
$I$ levels for any value of $T_{\text {winter }}$ enables the incorporation of a disease prediction model in combination with spatially-explicit climate models to produce disease prediction maps. Using this approach, a disease prediction map of $P$. gaeumannii abundance in 1- and 2-year old foliage based on the average DAYMET $T_{\text {winter }}$ values from 1980-1997 was produced for the northwest portion of the Oregon Coast Range (Fig. 7).

\section{DISCUSSION}

Infection studies with inoculated seedlings incubated under different levels of shade, misting, and irrigation resulted in differ-

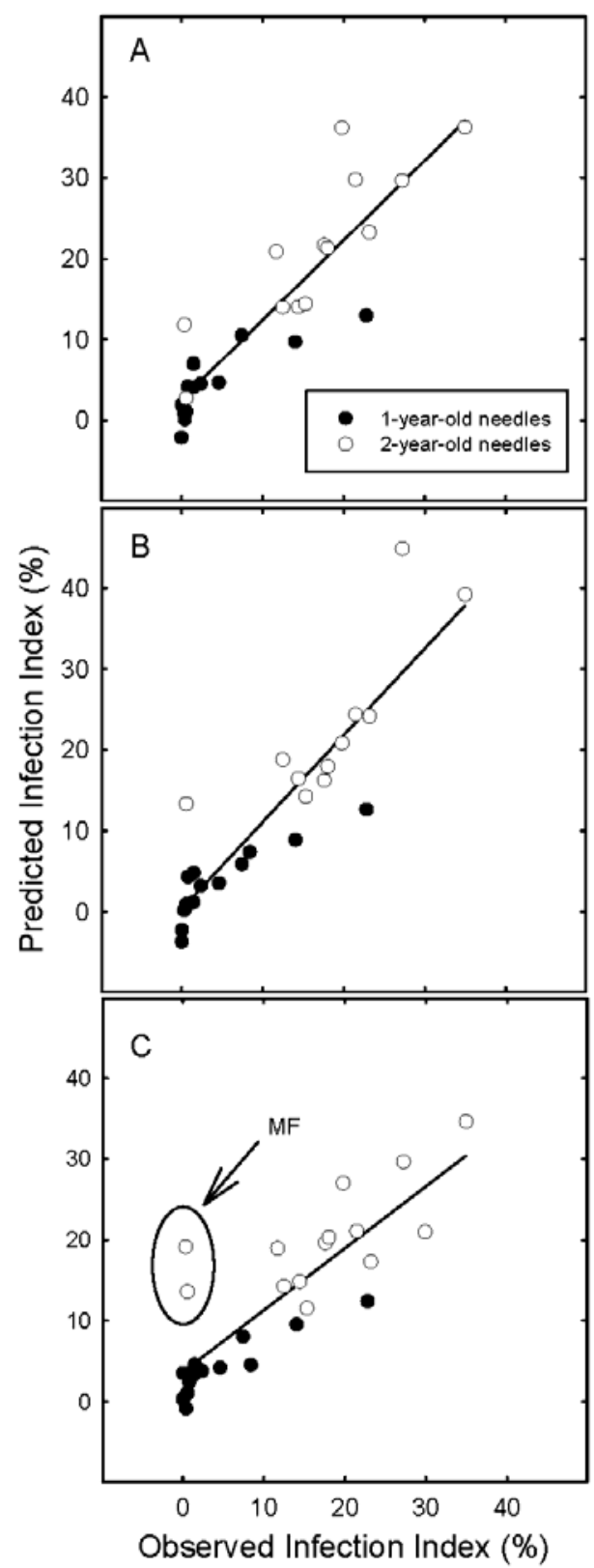

Fig. 3. Validation of infection index $(I)$ model predictions against observed infection data for seven coastal Oregon field sites from 2003-2004. Comparison between observed versus predicted Phaeocryptopus gaeumannii I. A, Climate-only model (1-year-old needles: $I=-18.1+5.86 \times 10^{-3}\left(L W_{\text {spring }}\right)+$ $3.38\left(T_{\text {winter }}\right)$, 2-year-old needles: $I=-30.0+2.35 \times 10^{-2}\left(L W_{\text {spring }}\right)+$ $\left.6.05\left(T_{\text {winter }}\right), R^{2}=0.802\right)$. B, Climate-disease model (1-year-old needles: $I=$ $-10.4+0.31\left(I_{\mathrm{y}-2}\right)+1.57\left(T_{\text {winter }}\right), 2$-year-old needles: $I=4.85+1.14\left(I_{\mathrm{y}-1}\right)+$ $\left.2.02\left(T_{\text {winter }}\right), R^{2}=0.812\right)$. C, Equilibrium model (1-year-old needles: $I=$ $13.7+3.36\left(T_{\text {winter }}\right), 2$-year-old needles: $I=-10.8+5.85\left(T_{\text {winter }}\right), R^{2}=0.701$ for all sites, 0.847 with the MacDonald forest site (circled) excluded. $\bullet=$ One-year-old needles and $\mathrm{O}=2$-year-old needles. ences in numbers of $P$. gaeumannii pseudothecia on foliage in the treatments after 10 months. Because all trees in the study received the same exposure to inoculum, the different postinoculation conditions differentially affected the rates of foliage colonization, development of pseudothecia by $P$. gaeumannii, or both. Contrary to our expectations, however, $P$. gaeumannii was most abundant in the full-sun, no mist treatment, and the amount of infection was not increased by additional surface moisture or irrigation. Because the pattern of $P$. gaeumannii abundance corresponded to treatment temperature rather than water availability, these results suggested that temperature, particularly between December and February, might be an important factor limiting the rate of foliage colonization by P. gaeumannii. Winter temperature of field study sites also was correlated with disease severity and abundance of $P$. gaeumannii, suggesting that variation in winter temperature across field study sites might differentially affect rates of $P$. gaeumannii development that, over time, could lead to differences in disease severity observed among sites.

The abundance of $P$. gaeumannii pseudothecia on needles is directly related to impaired $\mathrm{CO}_{2}$ uptake, the physiological basis for its pathogenicity. As an increasing proportion of stomata are occluded by pseudothecia, gas exchange and photosynthetic activity levels decrease, eventually resulting in needle abscission $(9,10)$. Sporulation of $P$. gaeumannii, therefore, is directly related to pathogenicity and so $I$, a measure of the proportion of needle stomata occluded by pseudothecia, is also a measure of disease severity. The abundance of pseudothecia on needles is also very closely correlated with biomass of $P$. gaeumannii in needles, as determined by various measures $(11,27)$. Therefore, on the basis of field observations and experimental evidence that temperature

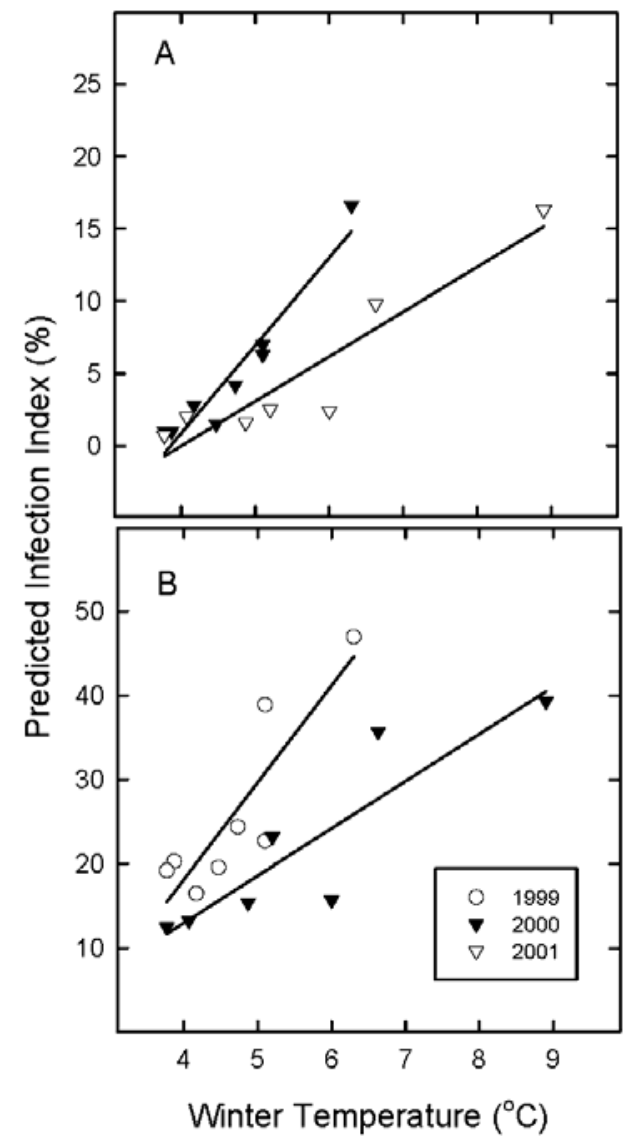

Fig. 4. Regressions between Phaeocryptopus gaeumannii infection index (I) and average mean-daily winter temperatures $\left(T_{\text {winter }}\right)$ by year for nine field sites used for monitoring Swiss needle cast. A, One-year-old needles. B, Twoyear-old needles. $\triangle=2001$ needle cohort, $\boldsymbol{\nabla}=2000$ needle cohort, and $\bigcirc=$ 1999 needle cohort. 
differentially influences the abundance of $P$. gaeumannii pseudothecia, we developed three predictive models for the estimation of $I$ in 1- and 2-year-old needles.

The climate-only model was based on mean $T_{\text {winter }}$ and cumulative spring $L W_{\text {spring }}$ and accounted for approximately $80 \%$ of the

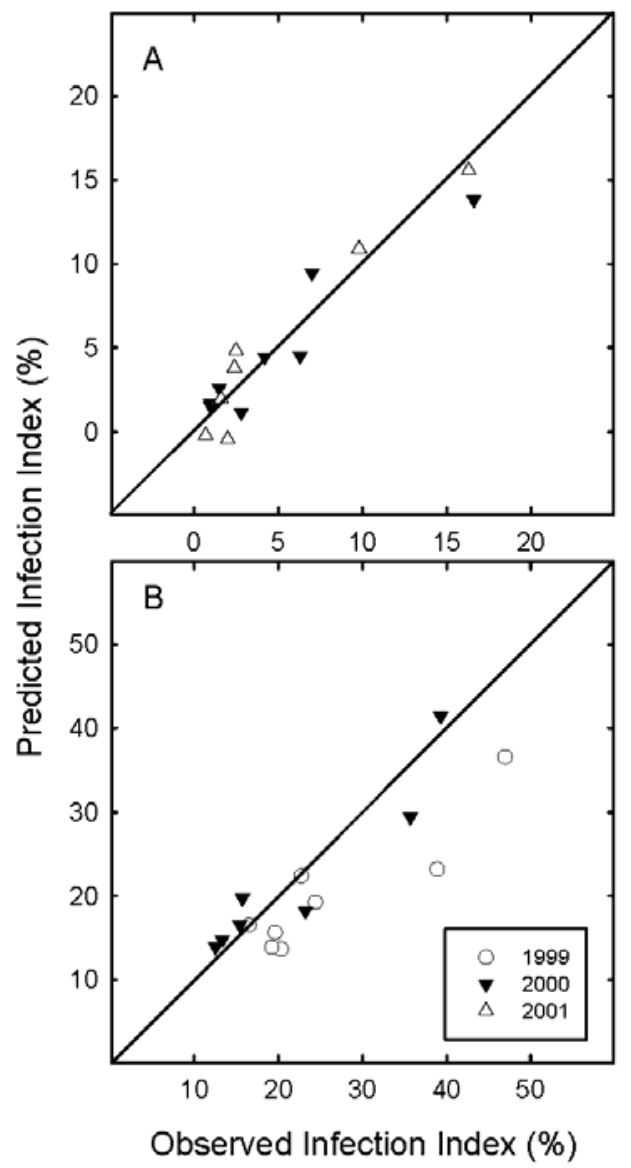

Fig. 5. Observed versus predicted Phaeocryptopus gaeumannii infection index (I) based on the combined climate-disease model for nine field sites used for monitoring Swiss needle cast levels in the Coast Range. A, One-year-old needles, $I=-10.4+0.31\left(I_{\mathrm{y}-2}\right)+1.57\left(T_{\text {winter }}\right), R^{2}=0.906$. B, Two-year-old needles, $I=4.85+1.14\left(I_{\mathrm{y}-1}\right)+2.02\left(T_{\text {winter }}\right), R^{2}=0.803 . I_{\mathrm{y}-2}$ is the $I$ of 2 -yearold needles, $I_{\mathrm{y}-1}$ is the $I$ for the modeled 2-year-old age class 1 year earlier, and $T_{\text {winter }}$ is average mean-daily winter temperature for the months of December to February. variation in $I$ observed for 1-and 2-year old needles (Fig. 3A). Because $L W$ measurements are frequently not available in public databases, or must be derived, we developed a climate-disease model based on a pair of equations that did not require $L W$ measurements. The climate-disease model explained approximately $81 \%$ of the variation observed in $I$ for 1 - and 2-year old needles (Fig 3B). The equilibrium model took advantage of the fact that the maximum value of $I$ for any value of $T_{\text {winter }}$ for the climatedisease model is linearly related to $T_{\text {winter }}$ and is independent of the initial value of $I$. This model accounted only for approximately $70 \%$ of the variation observed in $I$ for 1 -and 2 -year old needles at all sites, but the fit was improved to $85 \%$ by removing the most inland site, MacDonald forest (Fig. 3C). This suggests that this model may be more suitable for I predictions west of the Coast Range crest. Furthermore, because estimates of the maximum value of $I$ in 1- and 2-year-old needles can be generated based on $T_{\text {winter }}$ alone, this model could be used to produce disease risk maps and stimulate further hypothesis testing.

Most simplistically, the dynamics of fungal infection and colonization can be described by four components: inoculum exposure (concentration and duration), establishment efficiency (the proportion of spores that successfully infect the host), growth rate, and spore production. For infections in perennial foliage that may persist and increase over several years, an additional descriptive term may be needed. Biologically, the parameters in the models developed here correspond to a climate factor assumed to be related to fungal growth rate $\left(T_{\text {winter }}\right)$, a climate factor probably related to inoculum level and establishment efficiency $\left(L W_{\text {spring }}\right)$, and two indices of pre-existing $P$. gaeumannii colonization related to inoculum exposure $\left(I_{\mathrm{y}-2}\right)$ and colonization level at approximately 12 months $\left(I_{\mathrm{y}-1}\right)$. Colonization by $P$. gaeumanii (as measured by $I$ ) in needles 1 year after initial infection can be assumed to be determined primarily by inoculum exposure, which is related to amount of ascocarp production in 2-year-old needles $\left(I_{\mathrm{y}-2}\right)$, the establishment efficiency, which may be affected by $L W_{\text {spring }}$ and other unspecified factors and fungal growth rate, which is related to $T_{\text {winter }}$. Because new infections occur almost exclusively while needles are expanding during their first growing season $(2,6)$, the difference in $I$ between the first and second growing seasons is determined only by the $I$ at the beginning of the second year $\left(I_{\mathrm{y}-1}\right)$ and fungal growth rate.

The assumption that $T_{\text {winter }}$ is related to fungal growth rate in the models is supported by experimental observations on seasonal patterns of growth by $P$. gaeumannii. $P$. gaeumannii requires a minimum of 1 year to complete its development from ascospore germination to ascospore production; no conidial state is pro-
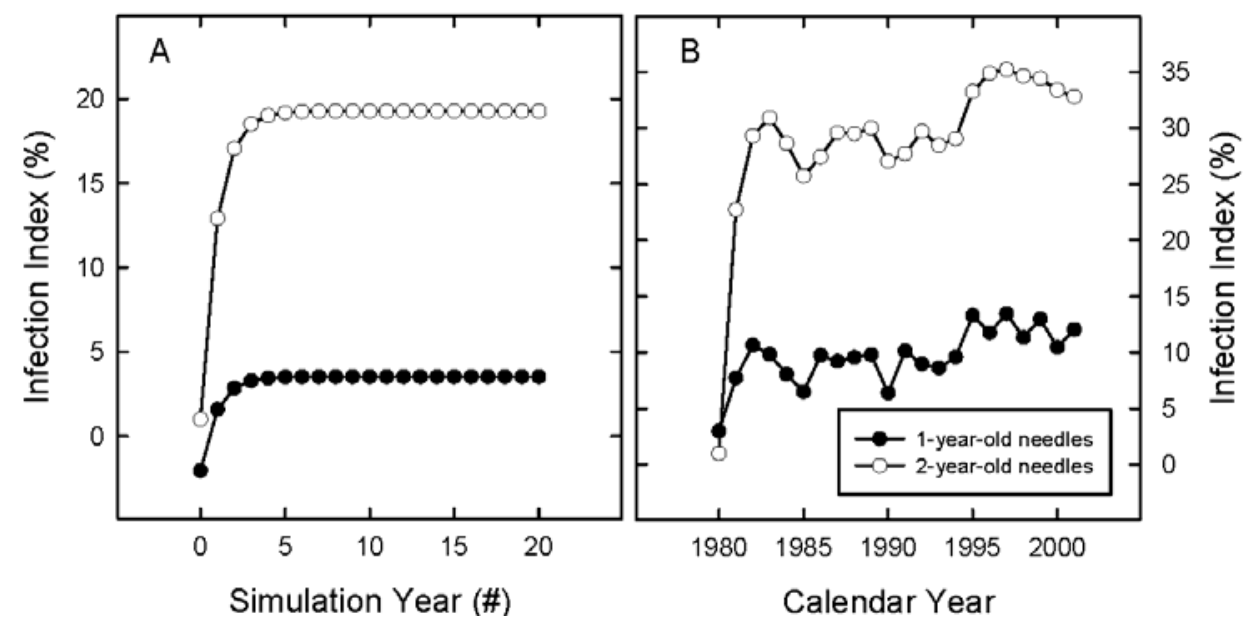

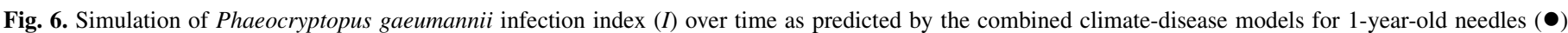

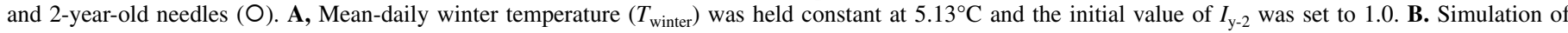

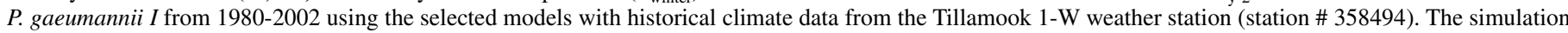
equations are described in Figure 5. 
duced $(1,2,6,15)$. The greatest divergence in abundance of pseudothecia in the seedling inoculation study occurred between December and February, a period during which internal and epiphytic hyphal growth occurs and pseudothecial primordia begin to develop (2). Colonization of the needle interior occurs continuously throughout the lifetime of the needle following its initial infection, with a secondary epiphytic growth phase beginning in the autumn and continuing through the winter months. Pseudothecial primordia are first visible forming in epistomatal chambers in late fall, at 4 to 5 months following initial infection. They continue to enlarge through the winter and spring, reaching maturation by early summer $(2,15,21,23)$. Colonization continues in subsequent years within needles that are not abscised, resulting in increasing numbers of pseudothecia formed on needles as they age $(1,2,15,27)$.

Because $T_{\text {winter }}$ was the single environmental factor most closely correlated with $I$, this suggests that growth of $P$. gaeumannii during the winter season is a significant factor limiting the observed distribution of Swiss needle cast disease in western Oregon. More rapid colonization of needles by $P$. gaeumannii should lead to more abundant production of pseudothecia, resulting in earlier needle abscission. More abundant pseudothecia also should result in a greater abundance of ascospores, and so greater inoculum pressure. Over time, disease levels between sites will diverge as a function of local conditions. It therefore seems reasonable that geographic variations in environmental determinants of pathogen growth rate could lead to predictable spatial patterns of disease severity in a long-lived, perennial host.

The equilibrium model appears to be suitable for predicting $I$ in Douglas-fir plantations west of the Oregon Coast Range crest using only one variable, $T_{\text {winter }}$. Other factors that have been identified in laboratory studies and field observations as being related to disease, such as precipitation, high humidity, and $L W_{\text {spring }}$ during the initial infection period, are presumed not to be limiting at critical periods in the infection cycle in Coast Range forests,

\section{One-year-old Needles}

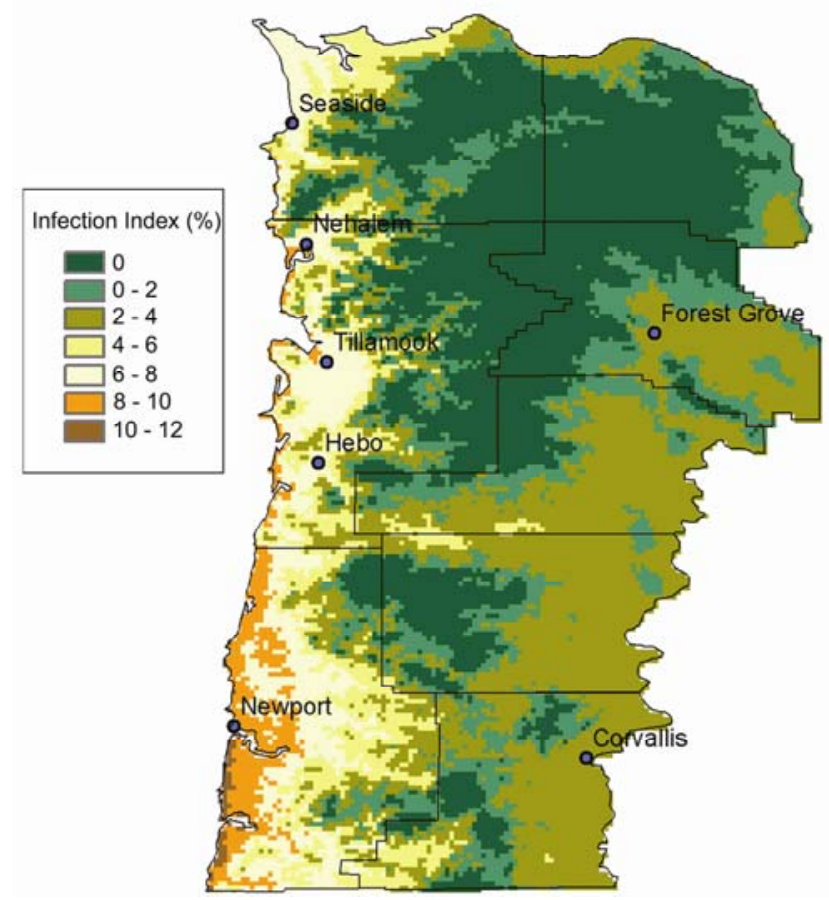

which typically experience abundant spring moisture. However, for predictions of $I$ for sites east of the Oregon Coast Range crest, a measure of inoculum level and establishment efficiency (e.g., $L W_{\text {spring }}$ or $I_{\mathrm{y}-1}$ and $\left.I_{\mathrm{y}-2}\right)$ may be needed for more accurate predictions. This appears to be the case for the MacDonald forest site (Table 1). This site is the easternmost study site and the only site in the rain shadow of the Coast Range. Although winter temperatures at this site were comparatively mild, actual $I$ levels for this site were less than predicted by the equilibrium model, deviating noticeably more than the other sites from the predicted values. When $L W_{\text {spring }}$ was included in the model, the predictive ability of the model was improved, suggesting that this parameter may be more important for disease predictions on interior sites (Fig. 3C).

One interesting property of the climate-disease model is that it predicts a rapid increase in $I$ up to a stable temperature-dependent equilibrium level for an initially disease-free site (i.e., low initial I). Such a scenario actually has been observed in a fungicide study installed by the Oregon Department of Forestry (22). In this study, three pairs of 2-ha (5-acre) blocks were delimited in a 15-year-old Douglas-fir plantation. One block in each pair was treated annually with an aerially applied fungicide (Bravo Weatherstik 720) for five consecutive years, 1997-2001. The second block of each pair was left as an untreated check. Fungicide treatments reduced the $P$. gaeumannii infection levels in 1- and 2-year-old foliage to less than $10 \%$ of that of unsprayed controls after 5 years. After annual spray applications were terminated, however, infection levels in the previously treated blocks quickly increased, and after 2 years without fungicide application, infection levels were not different from the unsprayed blocks.

The recent increase in Swiss needle cast severity in Oregon has puzzled pathologists because $P$. gaeumannii is an endemic pathogen of a native host not previously associated with severe disease in forest plantations. The disease triangle dictates that something must have changed with respect to host, pathogen, or environment

\section{Two-year-old Needles}

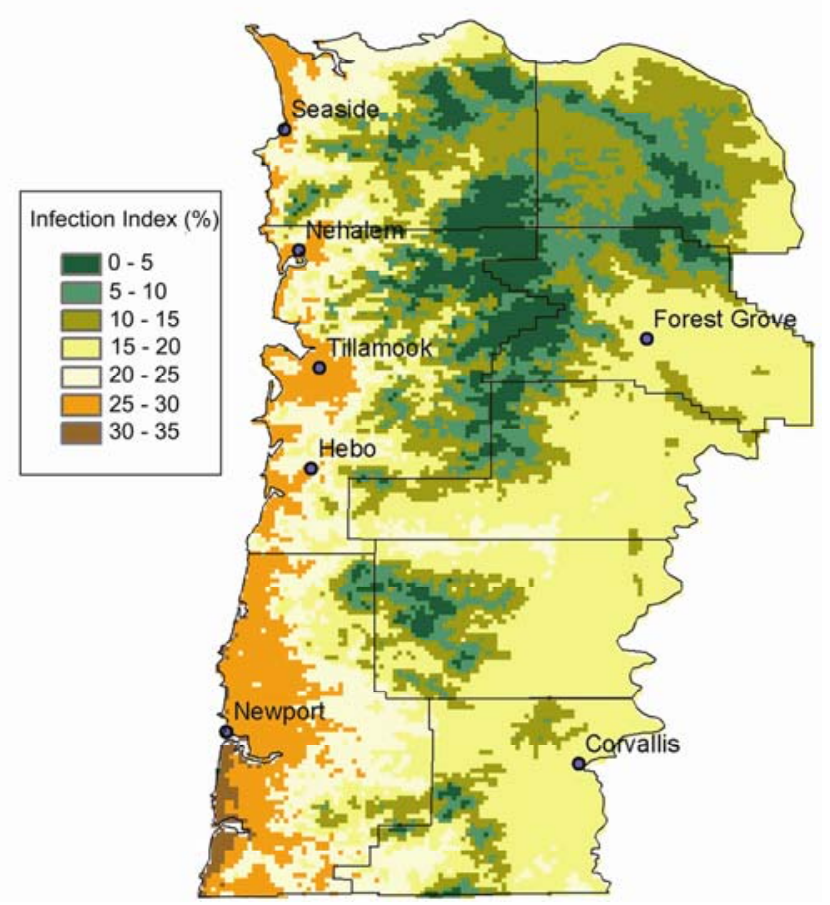

Fig. 7. Climate-based estimates of the temperature-dependent equilibrium levels of Phaeocryptopus gaeumannii infection in northwest Oregon. Infection indices (I) were predicted from average daily temperature (December to February) and the equilibrium models (1-year-old needles: $I=-13.7+3.36\left(T_{\text {winter }}\right), 2$-year-old needles: $I=-10.8+5.85\left(T_{\text {winter }}\right)$ ) derived from the climate-disease models shown in Figure 5. Temperature data is the 18-year average (1980 to 1997) estimated by the DAYMET model. 
since Boyce's (1) initial appraisal of Swiss needle cast on the Pacific Coast. The interior form of Douglas-fir (P. menziesii var. glauca (Beissn.) Franco) is known to be more susceptible to the disease than is the Coastal form ( $P$. menziesii var. menziesii (Mirb.) Franco) $(13,20)$, but the interior form is not grown for forestry in western Oregon and does not occur naturally in the Oregon Coast Range. Professional foresters are aware of the geographic variation in tree genotypes and the poor performance of trees planted outside of their native range, and since 1966, a program to certify forest tree seed by site of origin has been in place and used in conjunction with a seed zone map and seed transfer guidelines to aid foresters in the appropriate selection of locally adapted planting stock (17). Furthermore, although differences in Swiss needle cast symptom severity (needle loss) have been reported for provenances of the Coastal form of Douglas-fir (13), little variation in susceptibility to infection was found among provenances and families from the western Coast Range $(8,24)$. Thus, the widespread distribution of the disease in the western Oregon Coast Range, an area that encompasses multiple ownerships, stand ages, and management histories, suggests that planting of inappropriate seed sources is unlikely to be the primary cause of the recent epidemic.

However, an increasing amount of low elevation coastal land converted to Douglas-fir plantations on sites previously occupied by other species (western hemlock, Sitka spruce, red alder) may have contributed to recent increases in disease. Records of the historical distribution of Douglas-fir in the Oregon Coast Range are scant, but suggest that the species is more abundant now than earlier in the century due to changes in forest management. The Oregon Department of Forestry (ODF) (unpublished data) investigated the history of 76,970 ha of Douglas-fir plantations 10 to 30 years old growing within $29 \mathrm{~km}$ of the north Oregon Coast in 1997. Only approximately $20 \%$ were on sites dominated by Douglas-fir in the previous rotation; $80 \%$ of the Douglas-fir stands included in the 1997 ODF survey were sites previously occupied by other species. Much of the land that has been converted to Douglas-fir plantations in recent decades, and where the most severely diseased plantations are located, lies in the Picea sitchensis vegetation zone, a coastal forest type characterized by elevations generally below $150 \mathrm{~m}$, proximity to the ocean, and a moderate climate (3). If $P$. gaeumannii develops more quickly in trees occupying sites with milder winter temperatures, e.g., lowland sites, south slopes receiving winter sun, etc., more severe disease would be predicted on such sites. Therefore, an increase in acreage of Douglas-fir within the Picea sitchensis zone, together with climatic conditions more favorable for growth of the pathogen, may have contributed to the increase in $P$. gaeumannii above historical levels.

A separate study has investigated possible variations in virulence among genotypes of $P$. gaeumannii (26). The focus of the current study is whether environmental factors that affect pathogen growth and development may help account for the increased severity in Swiss needle cast recently observed along the Oregon coast. Although recent concern about Swiss needle cast in the Oregon Coast range started around 1990, the retrospective simulation of $P$. gaeumannii $I$ based on temperature measurements from Tillamook, OR between 1980 and 2002 indicates that conditions favorable for disease have fluctuated during the past 30 years. The simulation suggests that conditions for infection and development between 1995 and 2000 were the most favorable of the past 30 years, corresponding to unusually high levels of disease. Previous sporadic outbreaks of Swiss needle cast in Oregon and Washington have been related to periods of mild winters, but have been of much briefer duration $(4,19)$.

The apparent sensitivity of $P$. gaeumannii to small differences in winter temperatures suggests that increases in Swiss needle cast severity during the past two decades may have been affected by regional climate trends. Over the past century, temperatures averaged over the Pacific Northwest region have increased by approximately $0.8^{\circ} \mathrm{C}$, with the greatest changes occurring during the winter months (16). Average temperatures for the period of January to March have increased by approximately 0.2 to $0.4^{\circ} \mathrm{C}$ per decade since 1966 in the coastal area of Oregon and Washington (25). These annual and monthly averages can not be directly used to project changes in disease severity based on the winter average daily temperature disease prediction models, but do suggest a relationship between recent regional climate patterns and an observed increase in Swiss needle cast. An increase in average daily winter temperature of $1^{\circ} \mathrm{C}$ corresponds to an increase in $I$ of approximately 3.3 and $5.9 \%$ for 1 - and 2-year-old needles, respectively, based on the equilibrium model. Spring (April to June) precipitation in the coastal area of Oregon and Washington also has increased by 1.6 to $2.6 \mathrm{~cm}$ per decade since 1966 (25). These observations suggest that conditions have become increasingly more favorable for growth of $P$. gaeumannii and may have contributed to the regional increase in Swiss needle cast severity. If so, long range predictions of continued warming regionally of $1.5^{\circ} \mathrm{C}$ by 2020 and $2.3^{\circ} \mathrm{C}$ by 2040 , together with increased spring precipitation (16), suggests that Swiss needle cast disease severity is likely to continue to increase.

The disease prediction map based on the equilibrium model generally agrees with the distribution of disease symptoms as determined by aerial surveys (7), and thus will be useful in predicting disease impacts over different spatial scales. Furthermore, because of the effects of $P$. gaeumannii on $\mathrm{CO}_{2}$ uptake and growth reduction (10), the geographical information systems (GIS)-based disease severity models can help refine estimates of the impact of Swiss needle cast on regional carbon budgets. Based on empirical and theoretical relationships between proportion of occluded stomata and needle retention (10), the prediction map for $P$. gaeumannii can be used to derive a similar map for foliage retention, which then could be combined with other modeling tools for spatial prediction of Douglas-fir growth reduction due to Swiss needle cast. Refinement and testing of the infection models under a wider range of conditions is in progress. The simple models developed in this study are a first attempt to develop tools for predicting the distribution and severity of Swiss needle cast across the landscape under different climate scenarios and to generate explicit hypotheses for testing. The long-term objective of this research is to develop an integrated model that can be used as a management decision support tool to predict Douglas-fir growth and yield under fluctuations in annual weather conditions and varying disease intensities.

\section{ACKNOWLEDGMENTS}

This work was supported by the Swiss Needle Cast Cooperative of Oregon State University, and the Office of Science, Biological, and Environmental Research Program (BER), U.S. Department of Energy, through the Western Regional Center of the National Institute for Global Environmental Change (NIGEC) under Cooperative Agreement No. DE-FCO203ER63613. Financial support does not constitute an endorsement by the DOE of the views expressed in this article/report. We thank E. M. Hansen and K. B. Johnson for their critical reading of the manuscript and helpful discussions.

\section{LITERATURE CITED}

1. Boyce, J. S. 1940. A needle-cast of Douglas-fir associated with Adelopus gaeumannii. Phytopathology 30:649-659.

2. Capitano, B. 1999. The infection and colonization of Douglas-fir by $P$. gaeumannii. M.S. thesis. Oregon State University, Corvallis.

3. Franklin, J. F., and Dyrness, C. T. 1973. Natural Vegetation of Oregon and Washington. USDA For. Serv. General Tech. Rep. PNW-8.

4. Hansen, E. M., Stone, J. K., Capitano, B. R., Rosso, P., Sutton, W., Winton, L., Kanaskie, A., and McWilliams, M. G. 2000. Incidence and impact of Swiss needle cast in forest plantations of Douglas-fir in coastal Oregon. Plant Dis. 84:773-778. 
5. Hood, I. A. 1982. Phaeocryptopus gaeumannii on Pseudotsuga menziesii in southern British Columbia. N.Z. J. For. Sci. 12:415-424.

6. Hood, I. A., and Kershaw, D. J. 1975. Distribution and infection period of Phaeocryptopus gaeumannii in New Zealand. N.Z. J. For. Sci. 5:201-208.

7. Kanaskie, A., McWilliams, M., Sprengel, K., and Overhulser, D. 2004. Swiss needle cast aerial surveys, 1996 to 2004. Pages 7-12 in: Swiss Needle Cast Cooperative Annual Report 2004. D. Mainwaring, ed. College of Forestry, Oregon State University, Corvallis.

8. Kastner, W. W., Jr., Dutton, S., and Roché, D. M. 2001. Effects of Swiss needle cast on three Douglas-fir seed sources on a low-elevation site in the northern Oregon Coast Range: Results after five growing seasons. West. J. Appl. For. 16:31-34.

9. Manter, D. K., Bond, B. J., Kavanagh, K. L., Rosso, P. H., and Filip, G. M. 2000. Pseudothecia of Swiss needle cast fungus Phaeocryptopus gaeumannii physically block stomata of Douglas-fir, reducing $\mathrm{CO}_{2}$ assimilation. New Phytol. 14:481-491.

10. Manter, D. K., Bond, B. J., Kavanagh, K. L., Stone, J. K., Filip, G. M. 2003. Modeling the impacts of the foliar pathogen, Phaeocryptopus gaeumannii, on Douglas-fir physiology: Net canopy carbon assimilation, needle abscission and growth. Ecol. Mod. 154:211-226.

11. Manter, D. K., Stone, J. K., and Kelsey, R. 2001. Quantification of Phaeocryptopus gaeumannii colonization in Douglas-fir needles by ergosterol analysis. For. Pathol. 31:229-240.

12. Manter, D. K., Winton, L. M., Filip, G. M., and Stone, J. K. 2003. Assessment of Swiss needle cast disease: Temporal and spatial investigations of fungal colonization and symptom severity. J. Phytopathol. 151:344-351.

13. McDermott, J. M., and Robinson, R. A. 1989. Provenance variation for disease resistance in Pseudotsuga menziesii to the Swiss needle cast pathogen, Phaeocryptopus gaeumannii. Can. J. For. Res. 19:244-246.

14. Michaels, E., and Chastagner, G. A. 1984. Distribution, severity, and impact of Swiss needle cast in Douglas-fir Christmas trees in western Wahington and Oregon. Plant Dis. 68:939-942.

15. Michaels, E., and Chastagner, G. A. 1984. Seasonal availability of Phaeocryptopus gaeumannii ascospores and conditions that influence their release. Plant Dis. 68:942-944.

16. Mote, P. W., Canning, D. J., Fluharty, D. L., Francis, R. C., Franklin, J. F., Hamlet, A. F., Hershman, M., Holmberg, M., Ideker, K. N., Keeton, W. S., Lettenmaier, D. P., Leung, L. R., Mantua, N. J., Miles, E. L., Noble, B., Parandvash, H., Peterson, D. W., Snover, A. K., and Willard, S. R. 1999. Impacts of climate variability and change, Pacific Northwest. National At- mospheric and Oceanic Administration, Office of Global Programs, and JISAO/SMA Climate Impacts Group, Seattle, WA.

17. Randall, W. K. 1996. Forest tree seed zones of western Oregon. State of Oregon, Department of Forestry, Salem, OR.

18. Rosso, P., and Hansen, E. M. 2003. Predicting Swiss needle cast disease distribution and severity in young Douglas-fir plantations in Coastal Oregon. Phytopathology 93:790-798.

19. Russell, K. 1981. Swiss needle cast in Douglas-fir. Washington Department Nat. Resources, For. Land Management Rep. 279. Olympia, WA.

20. Stephan, B. R. 1997. Phaeocryptopus gaeumannii on Douglas-fir provenances. Pages 54-63 in: Foliage, Shoot and Stem Diseases of Trees, Proc. IUFRO WP 7.02.02. G. Laflamme, J. A. Bérubé, and R. C. Hamelin, eds. Canadian Forest Service Laurentian Forestry Centre, Information Report LAU-X-122, Sainte-Foy, QC, Canada.

21. Stone, J., and Carroll, G. 1987. Observations of the development of ascocarps in Phaeocryptopus gaeumannii and on the possible existence of an anamorphic state. Sydowia 38:317-323.

22. Stone, J., Reeser, P., and Kanaskie, A. 2004. Fungicidal control of Swiss needle cast in a 20-year-old forest stand. Pages 35-41 in: Swiss Needle Cast Cooperative Annual Report 2004, D. Mainwaring, ed. College of Forestry, Oregon State University, Corvallis, OR.

23. Stone, J., Reeser, P., Winton, L., Sutton, W., and Manter, D. 2001. Effect of climate on infection biology and epidemiology of Swiss needle cast. Pages 46-54 in: Swiss Needle Cast Cooperative Annual Report 2001, G. Filip, ed. College of Forestry, Oregon State University, Corvallis, OR.

24. Temel, F., Johnson, G. R., and Stone, J. K. 2004. The relationship between Swiss needle cast severity and level of Phaeocryptopus gaeumannii colonization in coastal Douglas-fir (Pseudotsuga menziesii var. menziesii). For. Pathol. 34:383-394.

25. U.S. Department of Commerce, National Oceanic and Atmospheric Administration, National Weather Service, Climate Prediction Center. 2005. U.S. Temperature and precipitation trends. Online publication.

26. Winton, L. M. 2001. Phylogenetics, population genetics, molecular epidemiology, and pathogenicity of the Douglas-fir swiss needle cast pathogen Phaeocryptopus gaeumannii. Ph.D. thesis. Oregon State University, Corvallis.

27. Winton, L. M., Manter, D. K., Stone, J. K., and Hansen, E. M. 2003. Comparison of biochemical, molecular, and visual methods to quantify Phaeocryptopus gaeumannii in Douglas-fir needles. Phytopathology 93:121-126 